\title{
Ética médica e imagenología
}

\author{
Horacio Lozano Zalce ${ }^{1}$
}

La ética médica, como pieza fundamental de la medicina contemporánea, ha generado cuatro principios básicos que la soportan: beneficencia, no maleficencia, respeto a la autonomía y justicia. Es decir, hacer el bien, no hacer el mal, respetar y dejar que participe el paciente en la toma de decisiones con respecto a su salud, y ejercer la profesión médica dando un balance de justicia individual y colectiva.

El sistema de salud es una compleja estructura de servicios generados por profesionales dentro de instituciones que emplean alta tecnología. La mentalidad del médico ha sido moldeada a trabajar bajo una línea: su conocimiento está basado en hechos colectivos, pero su actuar es individual. Se emplean pruebas clínicas y paraclínicas para confirmar o excluir una impresión diagnóstica, y se deben conocer los alcances, virtudes y defectos de las pruebas elegidas, con base en resultados estadísticos. El modelo pragmático de pensamiento del médico está centrado en la acción clínica, con la autoridad de emplear todos los recursos para tratar a un paciente; piensa que su accionar hará el bien y prefiere hechos basados en pruebas científicas más que caer en academicismos; se enaltece a la ciencia más que al beneficio individual.

La imagenología (anteriormente radiología) es una rama de la medicina considerada una especialidad como muchas otras; surgió de la necesidad de apoyar primordialmente a través de aplicaciones tecnológicas en el diagnóstico de las enfermedades. Resulta impensable la práctica médica contemporánea sin la presencia de la misma.

El entrenamiento y quehacer en la imagenología consisten en la identificación de las menores anomalías identificables y sugerir estudios complementarios hasta aclararlas. El riesgo es que los hallazgos pueden ser reales y secundarios a procesos de enfermedad, pero lamenta-

\footnotetext{
${ }^{1}$ Jefe del Departamento de Imagenología. Hospital Ángeles Lomas. Huixquilucan, Estado de México.
}

Correspondencia:

Dr. Horacio Lozano Zalce

Correo electrónico: hlozanozalce@gmail.com

Aceptado: 10-11-2016.

Este artículo puede ser consultado en versión completa en http:// www.medigraphic.com/actamedica blemente pueden reflejar artificios, variantes anatómicas, o bien, carecer de traducción clínica. La popular frase "el que busca encuentra" ejemplifica con gran facilidad esta premisa. La medicina se basa en identificar y monitorear lesiones (alteraciones anatómicas y/o funcionales), así como dar seguimiento a su comportamiento postratamiento; por ende, la imagenología se ha convertido en los "ojos" de la medicina. Cuando no existe la adecuada y eficiente comunicación entre los clínicos y los imagenólogos, surge información que podría ser deletérea en la atención integral al paciente. Por lo tanto, es impensable disociar los hallazgos de la imagen con las decisiones clínicas.

La tecnología crea sus propias necesidades e intereses, y nadie está exento de esta realidad, muchas veces profundamente enajenada. Se considera que la imagenología es la rama de la medicina que más desarrollo tecnológico tiene. Es, entonces, quehacer nuestro ponderar si la nueva tecnología es mejor que la anterior, así como emplearla con resultados aún no del todo validados. De forma lamentable, la práctica médica no está exenta de participar en la terrible carrera entre prestadores de servicios, con la presión que genera su propio mercado (incluyendo a los pacientes, el internet, las redes sociales, la televisión, etcétera).

La imagenología debe, al igual que el resto de las especialidades, estar basada en evidencias, a través de un largo y complejo camino: aplicación del pensamiento crítico, esclarecimiento de los hechos, justificación y verificación de los mismos.

La responsabilidad del imagenólogo frente al resto del gremio debe incluir el establecimiento de una relación que permita realizar e interpretar los estudios, proteger la confidencialidad del paciente, promover su actualización permanente, reconocer sus limitaciones y pedir ayuda, participar de manera muy activa con el resto del cuerpo médico con la finalidad de compartir conocimientos para poder, también, disminuir riesgos y aumentar la seguridad, y finalmente, fungir como el responsable (inclusive de forma legal) de la seguridad del enfermo y de los profesionales de la salud que participan durante los estudios (aplicación de medios de contraste, protección radiológica, etcétera).

Un lugar común dentro de las frases populares es: "ser un médico muy atinado", partiendo de que la definición de la palabra atinar de la Real Academia Española de la Lengua es: "Encontrar lo que se busca a tiento, sin ver el 
objeto". Lamentablemente, el enunciado se emplea como un cumplido.

Freeman publicó en una prestigiosa revista médica (NEJM, 1987) la siguiente frase: "Después de todo, la licencia de los médicos está basada en sus conocimientos probados, no en una superior capacidad para adivinar".

De todas estas ideas, me surgen las siguientes preguntas:

¿Todos los médicos están capacitados para validar, valorar, interpretar y responsabilizarse de los estudios de imagen y su contenido?

¿Es necesario que todos los estudios hayan sido interpretados por radiólogos?

La toma de decisiones clínicas debe estar basada en todos los elementos con los que se cuenta. ¿Realmente ocurre?

Las aseguradoras exigen al paciente que los estudios hayan sido interpretados por el especialista. ¿Es necesario?

Puedo dividir los retos para nuestra especialidad en los siguientes apartados: indicaciones de estudios, corresponsabilidad integral, establecer la relación riesgo-beneficio, tener claro el manejo de la información, realizar e interpretar los estudios, y finalmente, participar en la subsecuente toma de decisiones.

1. Indicaciones de los estudios: frente a la amplia gama de posibilidades y recursos de imagen, la selección debe ser cuidadosa y se debe reflexionar sobre la relación costo-beneficio y riesgo-beneficio. Es, entonces, fundamental contar con una comunicación permanente. El radiólogo debe ser honesto y autocrítico frente a su propia capacidad individual (experiencia), así como el entorno tecnológico con el que cuenta.

2. Corresponsabilidad integral: surge la pregunta: ihasta dónde debe el imagenólogo participar? Para participar debe conocer más al paciente y su historia, debe tener el aval del médico tratante, pero sobre todo, debe asumir el rol integral de interconsultante (opiniones, corresponsabilidad).

3. Relación riesgo-beneficio: cualquier procedimiento conlleva riesgos y beneficios. Los riesgos primordiales son daño inherente a la técnica empleada (sobre todo cuando se utiliza radiación ionizante), exposición a medios de contraste, mala elección del protocolo de exploración (por desconocimiento de datos clínicos o por ignorancia), efectuar estudios a un paciente en condiciones clínicas extremas. Los beneficios son que se cuenta con valiosa información que corrobora o excluye un diagnóstico, los resultados marcan la pauta terapéutica, aporta información colateral útil y marca el ritmo del seguimiento.

4. Manejo de la información: los pacientes nos preguntan y tienen todo el derecho de saber. Por ende, za quién debemos informar, al paciente, al médico, a ambos? No es infrecuente que el paciente, dentro de la esfera de confidencialidad, nos cuestione acerca de qué pensamos sobre su médico tratante, su enfermedad, su tratamiento, y lo allí vertido debe ser manejado con absoluta discreción. Es importante afirmar que en nuestro país, el dueño del estudio y su reporte es el paciente.

5. Realización e interpretación de los estudios: es imperativo reflexionar acerca del profesional (definido por la Real Academia Española como "persona que ejerce una actividad con relevante capacidad y aplicación"). Si partimos de esta base, los estudios deben ser realizados, dirigidos e interpretados por un individuo que haya recibido un entrenamiento formal. Entonces, ¿quién hace los estudios, en dónde?, ¿quién los interpreta? $\mathrm{Y}$, finalmente, iqué se hace con esa información? En México, la NOM-229-SSA1-2002 señala que "todo estudio que se solicita a un gabinete radiológico debe incluir: datos demográficos generales del paciente, datos clínicos con diagnóstico de presunción, estudio solicitado, datos del médico, incluyendo cédulas vigentes". También señala que "el médico radiólogo tiene la capacidad legal para valorar si el estudio es el óptimo para la patología que se busca, asumiendo la responsabilidad integral. Puede cancelar o postergar una exploración radiológica".

6. Participación en la subsecuente toma de decisiones: el quehacer del radiólogo debe traspasar su aparente esfera de comodidad. Debe buscar, mediante comunicación, participación y discusión, acercamiento con los médicos tratantes y ganarse la confianza del binomio médico-paciente. Esto se logra mediante los hechos, el trabajo y la responsabilidad.

Finalmente, quiero concluir con una discusión que los radiólogos vivimos todos los días. Si bien es claro que no tenemos la verdad absoluta y cometemos errores, nuestro entrenamiento profesional en imagenología nos pone en una situación de mayor claridad y ventaja para la valoración de los estudios propios de la especialidad.

Probablemente, el mayor riesgo para un paciente que será sometido a su estudio de imagen surge de la siguiente secuencia de eventos:

¿Quién realizó el estudio? $\rightarrow$ ¿Quién lo interpretó? $\rightarrow$ ¿Qué se hizo con la información que se generó?

Siendo consistentes y congruentes con los planteamientos ya explicados, me parece que la manera en que podemos cumplir con los preceptos éticos es promover la comunicación entre todos los implicados (siempre amplia, crítica, propositiva y multidireccional), así como incidir desde la 
educación médica inicial y hasta dentro de las especialidades. No podemos deslindarnos de esta realidad si queremos ser parte de una generación diferente de médicos.

\section{LECTURAS RECOMENDADAS}

1. Jackson W. The ethical radiologist. Diagnostic imaging. March 2015. Disponible en: Diagnosticimaging.com
2. Raymond J, Trop I. The practice of ethics in the era of evidence-based radiology. Radiology. 2007; 244 (3): 643-649.

3. Keer R. Ethical dilemmas in radiology and the vow to do no harm. ACR.org/news-articles. 2012.

4. Doucet H. Le Project d'une vie sans souf-france pour tous. Montréal, Canada: Les presses de l’Université de Montréal. 2002. pp. 31-47.

5. European Federation of Radiographer Societies. Código ético. Disponible en: http_/www.crisa-rx.com/código-etico-del-tecnico-en-radiologia/

6. Sociedad Europea de Radiología. Código ético. Disponible en: http:// www.myesr.org/html/img/pool/ESR_2012_ESRCodeofEthics-5.pdf). 